\title{
GEOGRAFIA E ECOLOGIA DA PAISAGEM: PONTOS PARA DISCUSSÃO
}

\section{Geography and Landscape Ecology: points for discussions}

\author{
Mariana Nascimento Siqueira \\ Aluna do Doutorado, Bolsista CNPq-Brasil \\ Universidade Federal de Goiás, Goiânia, Goiás, Brasil \\ mns.mariana@gmail.com
}

\author{
Selma Simões Castro \\ Profa. Titular, UFG. Bolsista Produtividade em Pesquisa CNPq \\ Universidade Federal de Goiás, Goiânia, Goiás, Brasil \\ selma.castro@uol.com.br \\ Karla Maria Silva Faria \\ Profa. Adjunta \\ Universidade Federal de Goiás, Goiânia, Goiás, Brasil \\ karlamsfaria@gmail.com
}

Artigo recebido em 14/06/2013 e aceito para publicação em 20/09/2013

RESUMO: O presente artigo pontua alguns aspectos que envolvem o conceito de paisagem visando contribuir para compreender a evolução conceitual do termo considerando a capilaridade entre Geografia e Ecologia da Paisagem. Desta enfatiza suas duas abordagens, a geográfica e a ecológica, correspondentes, respectivamente, à análise espacial dos elementos da paisagem e às alterações biológicas e relações ecológicas desencadeadas. Considera o termo Geoecologia como saída teórica e metodológica visando a integração dessas duas abordagens, as quais, no entanto, cada vez mais utilizam geotecnologias para identificação e mapeamento das unidades de paisagem, passo inicial imprescindível para sua análise. Chama a atenção para o fato de que a apropriação humana dos ecossistemas foi e ainda é tão intensa e tranformadora que hoje não é mais possível pensar em paisagem sem considerar esse fator no conceito, na estrutura e na dinâmica das paisagens.

Palavras Chave: Ecologia de Paisagem, Geoecologia, fragmentação, remanescentes, geotecnologias.

ABSTRACT: This paper discusses some aspects about the landscape concept and it contributions to understand the conceptual evolution of landscape according to geography and ecology. Respectively, these approaches, geographic and ecologic, emphasize the spatial analysis of landscape elements and the biological alteration and the ecological relations that are developed. Therefore, due to point view theorical and methodological, the Geoecology term has been rescued to integrate the geographic and ecological approaches. However, both approaches have used geotecnologies in identification and mapping of landscape units. Thus, it is possible to highlight that human appropriation of ecosystems is intense and transforming, therefore this factor must be considered in concept, structure and dynamic of landscapes.

Keysword: landscape ecology, Geoecology, fragmentation, remnant, geotecnologies. 


\section{INTRODUÇÃO}

Diferentes categorias de análise são objetos de estudos em Geografia, sendo uma delas a de paisagem, cujo conceito vem sendo discutido na Geografia desde o século XIX, principalmente visando entender o produto fisionômico das relações sociais e naturais em um determinado espaço e em sua dinâmica (SCHIER, 2003). Trata-se de um dos conceitos chaves da geografia, capaz de promover a unificação e identidade para afirmação da disciplina geográfica. Entretanto, como esta categoria não pertence exclusivamente à ciência geográfica, apresenta diferentes visões epistemológicas que possibilitaram distintas abordagens, aplicações e divergências entre as múltiplas abordagens geográficas (CÔRREA e ROSENDAHL, 1998; MARTINS et al., 2004; RODRIGUEZ et al., 2007). Em Ecologia, ecossistemas e paisagens são usados como as duas principais categorias de análise que permitem identificar unidades espaciais nas pesquisas ecológicas e práticas (NAVEH, 2010).

Os estudos de Carl Troll, na decada de 30, ao analisar as questões relacionadas ao uso da terra e interpretar as paisagens produzidas por essa relação, resultaram nas concepções da emergente disciplina científica, unificando os conceitos e campos de trabalho da geografia em relação à paisagem e da ecologia em relação ao ambiente natural, conclamando geógrafos e ecologistas a trabalharem em estreita colaboração, denominando a mesma de Geoecologia ou Ecologia da Paisagem.

Esta disciplina, no entanto, distingue duas principais abordagens: a geográfica, que privilegia o estudo da influência do homem sobre a paisagem e a gestão do território; e a ecológica, que enfatiza a importância do contexto espacial sobre os processos ecológicos e a importância destas relações em termos de conservação biológica (METZGER, 2001).

O desenvolvimento econômico e social humano, com fortes modificações impostas ao meio natural é comum na história da humanidade, sobretudo após a Revolução Industrial, que implicando em exploração agropecuária, ações de urbanização, implantação de infra-estrutura, transportes, energia e saneamento, resultou na redução progressiva da disponibilidade dos recursos naturais e no comprometimento crescente da qualidade de vida da própria sociedade humana e de seus territórios (FISZON et al., 2005; PIRES et al., 2006).

Vale a pena destacar que frente aos avanços da degradação da vegetação natural, e mesmo extinção de espécies, Tabarelli e Gascon (2005), AEM (2005), dentre outros, consideram a perda e a fragmentação de habitats como as maiores ameaças para a biodiversidade do planeta e consequentemente das paisagens. Assim, deve-se lembrar que a simplificação dos sistemas ecológicos e a alteração dos ecossistemas geram perda de funções ambientais benéficas à população humana e conseqüências deletérias em médio ou longo prazo (CERQUEIRA et al., 2005).

Portanto, considerando as relações homem e meio ambiente e as alterações ambientais provenientes do processo de apropriação e uso das terras, a presente revisão objetiva discutir a evolução conceitual das abordagens sobre paisagem, focando a necessidade de um tratamento multi e interdisciplinar que incorpore à Geografia as bases conceituais de Ecologia da Paisagem e vice-versa, dada a capilaridade entre ambos, considerando a atividade humana nos ecossistemas, realizando ainda uma análise sobre a apresentação das abordagens em eventos específicos dessa linha de pesquisa.

\section{NOTAS SOBRE OS ESTUDOS DE PAISAGEM E A GEOECOLOGIA}

No Brasil, Metzger (2001) apresentou um resumo das principais abordagens no conceito de paisagem, com o fim de facilitar o entendimento da evolução do termo na ciência, em especial na Ecologia da Paisagem. Ressalta ele que desde os poemas bíblicos de cerca de 1.000 anos A.C as primeiras citações da palavra paisagem já se referiam a uma interpretação visual e estética do visível ao olho humano, que se incorporou bem mais tarde, na segunda metade do século XVIII, à literatura, ciência e artes em geral. Moraes (1991) e Moreira (2004), dentre outros, já se reportaram ao mesmo para a Geografia. Portanto, o ponto de partida das duas ciências, Geografia e Ecologia, é o mesmo: paisagem é o que o ser humano vê.

Por isso, cientistas naturalistas ao viajarem em expedições ultramar, durante a fase do romantismo, levavam consigo pintores para auxiliar nas descrições 
pictóricas da natureza, com destaque para o geobotânico Alexander von Humboldt (1769 - 1854). Mas, esses cientistas buscavam, também, entender a dinâmica de funcionamento da natureza (CENE, 2009).

Nesse aspecto, Vitte e Silveira (2010) lembram que a proposta científica humboldtiana tinha como objetivo central a perspectiva da paisagem e que o conceito da mesma em suas obras acaba comportando dupla orientação, uma devido à importância do aspecto fisionômico e suas variações, que através de descrições e formas de representação da cena, nas feições e particularidades, diferencia as fisionomias da Terra; e outra, pelo papel ativo do olhar, que é criativo e subjetivo na captação e representação da paisagem descrita. Logo, paisagem é o que se vê, se descreve, se representa e se entende como se formou e como funciona.

Nucci (2007), ressalta, também, que os inventários provenientes destas observações e as explicações resultantes dos trabalhos experimentais, de campo e de laboratório, durante o século XIX, serviram de base para a primeira e a mais importante teoria integradora da biologia: a teoria da evolução.

No que se refere à Ecologia, convém destacar que a primeira teoria científica da evolução foi proposta por Lamarck (1744-1829) em 1809 e se baseava na prevalência dos fatores do meio físico e, em 1859, Darwin (1809-1882), apresentando uma irrefutável massa de provas, propõe a teoria da evolução com base na influência das relações entre organismos, levando à seleção natural. Darwin chamou a atenção para as infinitas, complexas e ajustadas relações mútuas de todos os organismos entre si e com as condições físicas de existência. Assim, Lamarck e Darwin definiram as duas grandes linhas da Ecologia e que são partes de sua definição clássica: o estudo das relações recíprocas entre os organismos e destes com o ambiente (NUCCI, 2007). Eis aqui um ponto chave.

Ferreira et al. (2001) revelam que apesar de paisagem ser uma preocupação antiga enquanto objeto de estudo, sobretudo da Geografia Física e Ciências da Terra, não recebeu uma atenção continuada, refletindo hoje nos objetos e métodos para fazer dela uma ciência propriamente dita. Uma espécie de vácuo científico ocorre na Geografia a respeito do uso do termo, quando os estudos do território assumem o foco principal da teoria e da pesquisa geográfica. Fato esse que parece ter favorecido o surgimento da recente Ecologia da Paisagem, tal como designada por Carl Troll (1939) e que em 1971 ele mesmo denominou de Geoecologia.

Segundo Nucci (2007), foi estudando questões relacionadas ao uso da terra por meio de fotografias aéreas e interpretação das paisagens em 1939, que Troll cunhou o termo Ecologia da Paisagem como uma disciplina científica. Mas, convém ressaltar que foi tentando unificar os conceitos e campos de trabalho da Geografia em relação à paisagem e da Ecologia em relação ao meio ambiente natural, que Troll conclamou geógrafos e ecologistas a trabalharem em estreita colaboração. Assim, foi possível a fundação de uma nova ecociência, objetivando unificar os princípios da vida e da terra, através de estudos da paisagem, que a partir de então apresenta novos conceitos (SOARES FILHO, 1998). Assim, é conveniente destacar o fato de que a Ecologia da Paisagem nasce conclamando geógrafos e ecólogos a trabalharem juntos na análise da paisagem.

Ecologia da Paisagem corresponde, portanto, ao estudo das inter-relações dos elementos físicos da paisagem como meio de vida. No entanto, não há consenso entre os cientistas, sobretudo entre geógrafos e ecologistas da paisagem. Assim, para entender a concepção científica de paisagem hoje, faz-se necessário focar em qual área da ciência que irá trabalhar os elementos da paisagem, pois como Martins et al. (2004) afirmam, "as ciências apresentam diferentes conceitos de paisagem" (p. 09). Segundo o autor, tais conceitos diversificam-se dependendo do contexto histórico e de sua aplicação em estudos específicos. Assim, as disciplinas que mais trabalham o tema, como Geografia Física, Ciências do Solo, Ecologia e Arquitetura, dentre outras, apontam para definições diferentes e de difícil comparação.

Isso significa que embora a base bíblica e do romantismo tenha tido entendimento comum sobre paisagem nas várias ciências, após isso os conceitos de paisagem não têm mais uma compreensão unânime porque pode ser interpretada até no sentido figurado, inclusive como paisagem política (FERREIRA et al. 2001). Entretanto, parece idéia comum a todas que as paisagens evoluem no tempo e no espaço.

Retomando essa noção de dinâmica evolutiva das paisagens, como produto integrado e construído 
pelas relações humanas com o meio, Bertrand (1972), ao considerar a paisagem como não sendo uma simples adição de elementos geográficos incoerentes e sim uma determinada porção do espaço, atribui-lhe unidade e identidade que a diferencia das vizinhas e de outras; ao considerá-la como o resultado da combinação dinâmica e instável de elementos físicos, biológicos e antrópicos, considera-a como produto das relações entre a sociedade e a natureza; e que, ao reagirem dialeticamente uns sobre os outros, fazem da paisagem um conjunto único e indissociável, em perpétua evolução, sendo produto da história, portanto é dinâmica no tempo e no espaço. Neste sentido, pode-se dizer que a paisagem seria então construída pela sociedade no tempo histórico. Esse autor chega mesmo a propor uma classificação taxonômica segundo as ordens de grandeza dos fenômenos espaço-temporais na superfície terrestre.

Nesse mesmo sentido, Naveh e Lieberman (1984) entendiam que a intenção de Troll ao incentivar uma colaboração entre a Geografia e a Ecologia, era combinar na prática, a aproximação horizontal (como interação espacial dos fenômenos) do geógrafo, com a aproximação vertical (como interações funcionais de um dado lugar, ou ecótopo) dos ecólogos. Formam e Godron (1986) complementam que estudos do relacionamento espacial entre elementos de paisagem a partir da estrutura horizontal da paisagem, relacionam-se à distribuição de objetos ecológicos (fauna, flora e biomassa), energia calórica e nutrientes, com o tamanho, forma, número, tipo e a configuração das manchas, corredores e matriz. Segundo esses autores, estas últimas são as unidades de paisagem. Isso significa que as paisagens podem ser mais do reconhecidas, podem ser classificadas.

Nucci (2007), esclarecendo sobre o surgimento e a importância da Ecologia da Paisagem enquanto ciência lembra que geógrafos e ecólogos na Europa Central, após a II Guerra Mundial, procuravam construir uma noção de Ecologia da Paisagem como uma ciência interdisciplinar que conduzisse a um inter-relacionamento entre a sociedade humana e seu espaço de vida, suas paisagens construídas ou não. Ressalta ainda que o $1^{\circ}$ Congresso Internacional de Ecologia da Paisagem, organizado pela The Netherlands Society of Landscape Ecology, foi realizado em
1981 em Wageningen (Holanda), conduzindo a criação da International Association of Landscape Ecology (IALE) em 1984. A partir de então, uma importante contribuição para esse campo foi o estabelecimento de áreas especiais para a Ecologia da Paisagem nas principais universidades da Alemanha, cujo objetivo foi considerar o complexo inter-relacionamento entre o homem e suas paisagens naturais, culturais e industriais, com a inclusão das demandas naturais, culturais e sócio-econômicas e, ao mesmo tempo, o enriquecimento do ambiente biótico natural.

Assim, Nucci (2007) apóia os pensamentos de autores como Naveh e Lieberman (1984), ao defenderem a necessidade de inclusão do ser humano e sua dimensão cultural-social e econômica como parte integrante da paisagem. Por outro lado, o autor critica a escola americana por excluir propositalmente o ser humano de sua pesquisa, exemplificando com a obra Ecologia da Paisagem de Forman (1995) e um capítulo de livro escrito por Pearson (2002) que se propõe a ensinar conceitos e técnicas em Ecologia da Paisagem, excluindo as ciências sociais e humanas.

No próprio seio da Ecologia da Paisagem não há consenso. Metzger (2001) alerta que as definições de Ecologia da Paisagem variam em função da abordagem dos autores, sobretudo distribuídas entre as duas abordagens, a geográfica e a ecológica. Afirma que uma abordagem geográfica é menos centrada em estudos bioecológicos (relação entre a biota e o meio abiótico), e pode ser definida como uma disciplina holística, integradora de ciências sociais, geofísicas e biológicas, visando em particular, a compreensão global da paisagem (essencialmente cultural) e o ordenamento territorial. Já uma abordagem ecológica foi inicialmente influenciada pela ecologia de ecossistemas, modelagem e análise espacial. Assim, é dada uma maior ênfase às paisagens naturais ou a unidades naturais de paisagem, à aplicação de conceitos para a conservação da diversidade biológica e o manejo de recursos naturais, não enfatizando obrigatoriamente as macro-escalas. Vale assinalar que seu desenvolvimento beneficiou-se bastante do advento das imagens de satélite (em 1970 - 1980) e das facilidades de análises geoestatísticas.

Nucci (2007), ainda pondera que essa mesma divisão se repete nas escolas do Brasil, pois quando 
ele realizou levantamento dos títulos das pesquisas publicadas no Caderno de Programas do VI Congresso de Ecologia do Brasil, realizado em 2003 na cidade de Fortaleza, dos 1.324 trabalhos, aproximadamente $2 \%$ estavam relacionados diretamente com questões sócio-econômicas e os trabalhos apresentados na área da Ecologia da Paisagem carregam, principalmente, a visão da escola americana quantitativa e voltada somente para os aspectos biológicos, onde o ser humano quase nunca tem vez, com as limitações conceituais e metodológicas.

Atualmente, tem aumentado a abordagem multidisciplinar e socioeconômica em pesquisas em ecologia da paisagem. Ao analisar-se os trabalhos publicados no Latin American IALE Conference realizado em 2009, na cidade de Campos do Jordão, SP, verifica-se que dos 274 trabalhos publicados neste evento, $23 \%$ apresentavam uma abordagem geográfica (aproximação horizontal), 38\% uma abordagem ecológica (aproximação vertical) e 39\% apresentam uma abordagem multidisciplinar. Estes últimos distribuem-se, principalmente, em pesquisas em geoecologia; programas, políticas ou softwares em planejamento ambiental ou científico; políticas públicas e etnociência. Dentre todos os estudos analisados, 25,2\% já carregam questões sócio-econômicas.

Essa necessidade de entender os processos sócio-espaciais na Ecologia da Paisagem, a abordagem geográfica é cada vez mais necessária para entender não só as transformações, mas o porquê destas, pois ao se remeter a ecólogos como Ricklefs (1996), o mundo físico e a dependência do biótico com o abiótico e vice-versa, permitem compreender que o mundo físico tanto proporciona o contexto para a vida como também limita sua expressão. Percebe-se que o autor define ainda ecologia como sendo o estudo do meio ambiente natural e das relações dos organismos uns com os outros e com seus arredores. Todavia, devido ao estágio avançado de antropização do meio ambiente natural, torna-se impossível excluir a ação do homem da ecologia de paisagem.

Classificar os ecossistemas naturais é tarefa comum aos ecólogos, mas identificar as unidades de paisagem, quando os ecossistemas foram tão profundamente transformados e permanecem evoluindo, é tarefa de geógrafos, mas é árdua, mas certamente é mais rica se for interdisciplinar, minimamente integrando Geografia e Ecologia da Paisagem, ou numa concepção integradora dos dois componentes da paisagem, o físico e biótico e o humano e social. Talvez a denominação dessa ciência mais agregadora no momento seja a Geoecologia que tem um viés mais geográfico (RODRIGUES et al., 2001), embora alguns geógrafos prefiram Ecogeografia (ROSS, 2006).

Quanto às unidades de paisagem as mais agregadoras parecem ser os geossistemas para os geógrafos, desde que integrem o ser humano como fator, seguindo a proposta de Bertrand (1972, 2004). Mas na Ecologia da Paisagem os ecólogos vêm propondo outra alternativa, como se verá a seguir.

\section{AS UNIDADES GEOECOLÓGICAS DE PAI- SAGEM}

Ao analisar uma paisagem ou qualquer outra composição física, biológica ou química espacializada faz-se necessária a descrição, identificação e classificação dos componentes que os constituem, o que nada mais é do que a sua taxonomia. Diante da análise e síntese da paisagem, Bertrand (2004) considerava a taxonomia das paisagens como tendo dominância física na qualidade de fixar limites e preconizava que o sistema de classificação escolhido, comportava seis níveis têmporo-espaciais ou ordens de grandeza: de um lado as unidades superiores: zona $\left(1^{\mathrm{a}}\right)$, domínio $\left(2^{\mathrm{a}}\right)$ e região $\left(3^{\mathrm{a}}\right)$; do outro as unidades inferiores: geossistema $\left(4^{\mathrm{a}}\right)$, geofácies $\left(5^{\mathrm{a}}\right)$ e géotopo $\left(6^{\mathrm{a}}\right)$.

Cabe destacar, que além das pesquisas terem se dedicado mais às unidades inferiores, os geossistemas representam melhor as integrações de fatores físicos (geomorfológicos, climáticos e hidrológicos) com suas dinâmicas. Trata-se, portanto, de uma unidade dimensional compreendida entre alguns quilômetros e algumas centenas de quilômetros quadrados. Segundo Bertand (2004) “ “...] é nesta escala que se situa a maior parte dos fenômenos de interferência entre os elementos da paisagem e que evoluem as combinações dialéticas mais interessantes para o geógrafo" (p.06). Nos níveis superiores a ele só o relevo e o clima importam e, acessoriamente, as grandes massas vegetais. Nos níveis inferiores, os elementos biogeográficos são capazes de mascarar as combinações de conjunto. 
Enfim, o geossistema constitui uma boa base para os estudos de organização do espaço porque ele é compatível com a escala observação.

Metzger (2001), perseguindo essa mesma idéia, enfatiza que a abordagem geográfica na Ecologia da Paisagem veio contribuir com o planejamento da ocupação territorial através da compreensão dos limites, das potencialidades e do uso econômico das unidades de paisagem. O autor entende que as unidades de paisagem são espaços do ecossistema com características hidrogeomorfológicas comuns e históricos de ocupação humana semelhante. Logo, a unidade de paisagem na abordagem geográfica pode ser considerada uma paisagem da abordagem ecológica, sendo esta formada por um mosaico heterogêneo de componentes (manchas, corredores e matriz) interativas, cuja heterogeneidade seja observável ao menos em um fator de uma determinada escala. Antrop (2007), ao realizar um apanhado sobre os últimos 25 anos da evolução da Ecologia da Paisagem, ressalta que o modelo de mancha - corredor - matriz e as métricas para medi-los chamadas de métricas da paisagem, têm sido a abordagem predominante para descrever o arranjo espacial dos elementos discretos (manchas) nas duas últimas décadas.

Manchas podem ainda ser definidas como superfícies não lineares que diferem de seu entorno. São resultados das combinações dos mecanismos de evolução de uma paisagem (processos geomorfológicos, geológicos, padrões de colonização de organismos e perturbações ecossistêmicas) que resultam em uma paisagem terrestre composta por diferentes formas de relevo, tipos de vegetação e uso do solo organizados em um arranjo ou mosaicos (manchas) que formam um agrupamento único de ecossistemas em interação. Estas manchas variam de tamanho, forma, tipo, heterogeneidade e características de borda, além de se encontrarem sempre embebidas em uma matriz com diferente estrutura e composição (FORMAM, GODRON, 1986).

Corredores são formados pela ligação entre elementos de uma mesma classe que estabelecem numa paisagem o fator de conectividade, função de configuração de redes. Assim, os corredores permitem o movimento e intercâmbio genético entre animais e plantas e as barreiras inibem as trocas. Algumas características relevantes dos corredores incluem a largura, conectividade, complexidade e estreitamento (SOARES FILHO, 1998).

A noção de matriz surge do conceito de conectividade e da ligação entre as manchas, como numa visão de fragmentos existentes dentro de uma massa. Assim, a matriz de uma paisagem pode ser definida como o elemento mais extensivo e conectado e que possui o papel preponderante no funcionamento de uma paisagem. Além de ter uma área bem mais extensa e com elementos côncavos envolventes a outros elementos, a matriz também pode ser caracterizada pela sua maior conectividade e pelo seu controle preponderante sobre o fluxo de energia e na dinâmica da paisagem (FORMAM, GODRON, 1986).

Portanto, o mosaico de manchas composto por elementos de paisagem (FORMAM, GODRON, 1986) ou as unidades de paisagem (METZGER, 2001) ou ecótopos ou ainda biótopos, nada mais são que uma área ocupada por uma biocenose (CERQUEIRA et al., 2005), a qual define o padrão estrutural de cada paisagem, pois que diversas paisagens formadas por distintos processos geomorfológicos, regimes de perturbação e atividades antrópicas possuem em comum essa estrutura fundamental (BERTRAND, 2004).

Nesse mesmo sentido, Metzger (2001) entende que o maior desafio atual da Ecologia da Paisagem é o estabelecimento de uma teoria de mosaicos, buscando entender como os diferentes padrões de organização espacial de seus continentes (as unidades de paisagem) influem sobre seu funcionamento. Desta forma, a Ecologia da Paisagem procura testar uma das propriedades fundamentais da teoria hierárquica, buscando distinguir grandes tipos de paisagens baseados no modelo de mancha - corredor - matriz.

A Geografia, desde o conceito de geossistemas, não parece ter elaborado uma nova proposta sobre as paisagens e sua classificação, apenas disputas entre escolas de pensamento sobre conceitos, além de ter preferido adotar unidades de estudo como bacias hidrográficas e territórios como objetos (SANTOS, 1992). Por outro lado, do lado dos ecologistas a conservação da biodiversidade parece ser o mote dos estudos das paisagens, o que significa que não é a paisagem em si que é o alvo, mas o instrumento de avaliação do grau de conservação dos habitat (OLIFIERS, 
CERQUEIRA, 2006). Resgatando Troll (1939) a Geoecologia parece contemplar as duas abordagens, a geográfica e a ecológica, integrando-as e nesse sentido não podendo ser sinônimo de Ecologia da Paisagem.

Olifiers e Cerqueira (2006) entendem a paisagem do ponto de vista dos seres vivos e acreditam que as paisagens naturais são mosaicos natural ou artificialmente fragmentados, onde há uma diferença marcante entre a heterogeneidade ambiental representada pelos mosaicos naturais e aqueles mosaicos induzidos pela fragmentação antrópica. Portanto, as principais conseqüências sobre a biodiversidade estão vinculadas ao tamanho dos remanescentes, isolamento dos mesmos, à matriz ou entorno do fragmento, à forma e ao efeito de borda dos remanescentes. Logo, o que mais interessaria é a estrutura das paisagens. Aliás, também do ponto de vista da abordagem geográfica da ecologia da paisagem, como do planejamento ambiental.

Um ramo relativamente novo da investigação estrutural da paisagem tem avançado bastante, que é o estudo das métricas de paisagem, o qual lida com as características e as mudanças da estrutura de mosaico espacial de um dado ambiente. Deste ramo surgiram várias ferramentas com valor crescente para o planejamento de paisagem durante os últimos 10 a 15 anos (CSORBA, 2008). Como suporte instrumental, vários programas e geotecnologias têm sido cada vez mais utilizados na avaliação das métricas da paisagem, dentre eles o Fragstats, que é um programa de domínio público. Como outros programas similares ele realiza cálculos estatísticos espaciais, tendo sido projetado para quantificar a composição, configuração e conectividade dos objetos espaciais a partir de uma imagem raster (MCGARIGAL, MARKS, 1995). Portanto, é de interesse inequívoco para estudo de fragmentação de paisagem.

A implementação de uma interface personalizada simples tem permitido que gerentes de recursos naturais e cientistas possam analisar as conseqüências do desenvolvimento numa paisagem ecológica. $\mathrm{Na}$ Universidade Federal de Goiás, pesquisas recentes sobre a dinâmica da paisagem no Bioma Cerrado com a utilização do Fragstats tem sido desenvolvidas, como as de Carvalho et al. (2009), Cabacinha et al. (2010), Faria et al. (2010), Carneiro et al. (2011) e Faria (2011).
A análise do processo de fragmentação ou de remanescentes do bioma Cerrado, por exemplo, é um dos campos de maior aplicação desse tipo de estudo. Envolve, portanto, uma análise socioambiental que se utiliza da Geografia como contexto político e socioeconômico de apropriação histórica dos recursos naturais nos territórios, e das tecnologias espaciais com dados e imagens obtidas pelos sensores orbitais e tratados em SIG, os quais se tornaram aliados do mapeamento da cobertura vegetal $\mathrm{e}$ de uso do solo (MESQUITAJÚNIOR, 1998). E utiliza-se da Ecologia da Paisagem numa abordagem geográfica quando analisa as métricas dos fragmentos para identificar unidades de uma dada paisagem e avaliar o status da conservação e de recuperabilidade de áreas degradadas, sobretudo para fins de conservação da biodiversidade. As interfaces com a Geografia Cultural, embora incipientes, parecem estar evoluindo, desde que tais estudos se apliquem à conservação dos saberes das populações tradicionais sobre a biodiversidade. Acrescente-se a isso que a geotecnologias e geoestatística vêm permitindo a elaboração de cenários futuros, que incluem a dinâmica evolutiva com e sem intervenção humana no sentido de promoção do equilíbrio geoecológico.

Pelo exposto, ainda há discussões a serem feitas, mas certamente num contexto aberto à interdisciplinaridade, porém desde que as disciplinas definam mais claramente suas posições. Resgatar a Geoecologia parece ser uma alternativa teórica e conseqüentemente metodológica, para a análise da paisagem, sua classificação e aplicação ao planejamento, sobretudo quando se trata de estudar os remanescentes das coberturas originais.

\section{CONSIDERAÇÕES FINAIS}

À medida que a apropriação da natureza foi sendo conduzida pelo homem, transformações nos elementos da paisagem e na dinâmica das relações entre a sociedade e a natureza ocorreram devido aos novos usos do solo implantados nos sistemas naturais, demandando a incorporação do fator humano na formação e explicação da dinâmica atual das paisagens. Nesse sentido, muitas áreas de coberturas vegetais originais foram suprimidas e convertidas em outros usos, exceto os remanescentes, dando lugar a uma paisagem fragmentada, sendo os fragmentos dos mais diversos tamanhos, formas e graus de isolamentos. 
A Geografia, desde a proposição dos geossistemas como unidades de paisagem, quando incorpora o fator humano na sua construção, não tem dedicado grande atenção aos estudos das paisagens, exceto alguns geógrafos físicos que trabalham com uma abordagem sistêmica, isto é integradora dos componentes das paisagens. Já a Ecologia da Paisagem apesar de conter duas abordagens, a ecológica (das espécies) e a geográfica (espacial), absorveu mais a primeira. Mas, evoluiu mais no sentido de analisar a estrutura da paisagem através de métricas das paisagens para avaliar sua estrutura espacial e composição com base na análise da fragmentação, ao incorporar o resultado do uso dos recursos naturais e a ocupação humana formando territórios. Cria e prioriza conceitos como manchas, corredores e matrizes e a aplicação de suas métricas para a classificação das paisagens e o planejamento ambiental, porém, mais na perspectiva da conservação da biodiversidade.

Como a fragmentação da paisagem envolve causas e efeitos tanto físicos como biológicos, a linha geográfica da Ecologia da Paisagem analisa a disposição espacial dos elementos na paisagem através das referidas métricas. Logo, a base geográfica permite subsidiar a abordagem ecológica, mas apenas quando investiga as alterações biológicas e interações ecológicas resultantes das mudanças ocorridas nos elementos da paisagem.

A Geoecologia parece ser a alternativa interdisciplinar para a integração das duas abordagens da Ecologia da Paisagem e a da Geografia, em termos de explicação das causas das categorias espaciais resultantes da ocupação humana, do uso dos componentes físicos, bióticos e culturais visando a compreensão do ordenamento espacial.

\section{AGRADECIMENTOS}

$\mathrm{O}$ artigo resulta de pesquisas financiadas pelo CNPq-Brasil e FAPEG-Goiás.

\section{REFERÊNCIAS}

ANTROP, M. Reflecting upon 25 years of landscape ecology. Landscape Ecology 22: 1441-1443, 2007.
ANTROP, M. Avaliação Ecossistêmica do Milênio (AEM). Relatório-Síntese. Disponível em: $<$ http:// www.millenniumassessment.org>. Acesso: 31 de maio de 2011.

BERTRAND, G. Paisagem e geografia física global. $R A^{\prime} E$ GA. Curitiba, n.8, p.141-152, 2004.

BERTRAND, G. Paisagem e geografia física global: esboço metodológico, Caderno de Ciências da Terra, v.13, p.1-27, 1972.

CABACINHA, C. D.; CASTRO, S. S.; GONÇALVES, D. A. Análise da estrutura da paisagem da alta bacia do Araguaia na savana brasileira. Floresta, v. 409(4), p.675-690, 2010.

CARNEIRO, G. T.; CABACINHA, C. D.; FARIA, K. M. S.; SIQUEIRA, M. N.; LIMA, J. C. S. Cobertura florestal do município de Rio Verde, GO: estrutura e composição da paisagem entre 2005 e 2008. Geografia, v. 36, n.2, p.335-357, 2011.

CARVALHO, F. M. V.; DE MARCO, P.; FERREIRA JUNIOR, L. G. The Cerrado into-pieces: habitat fragmentation as a function of landscape use in the savannas of central Brazil. Biological Conservation. n.142, p.1302-1403, 2009.

CENE, V.R.; VITTE, A.C. A representação cartográfica da paisagem em Alexander von Humboldt: uma contribuição à história da geografia. In: Anais XII EGAL - Encuentro e Geógrafos de América Latina, Montevideo, p.1-16. 2009.

CERQUEIRA, R., ANTONINI, Y.; FERNANDES, R. V.; FONTENELLE, J. C. R.; GODOY, F.; HASS, A.; LANDAU, E. C.; OLIVEIRA, P. P.; PINTO, J. R. R.; RAMBALDI, D. M.; RIBON, R.; SAMPAIO, A. B.; SANTOS, F. A. M.; SCARIOT, A.; SEVILHA, A. C. Glossário. In: RAMBALDINI, D. M.; OLIVEIRA, D. A. S. Fragmentação de ecossistemas: causas, efeitos sobre a biodiversidade e recomendações de políticas públicas. Brasília: MMA/SBF, $2^{\mathrm{a}}$ ed., 2005. 
CÔRREA, R. L.; ROSENDAHL, Z. (org). Paisagem, tempo e cultura. Rio de Janeiro: Ed. UERJ, 1998.

CSORBA, P. Potential applications of landscape ecological patchgradient maps in nature conservational landscape Planning. AGD Landscape \& Environment. 2(2): 160-169, 2008.

FARIA, K. M. S. Paisagens Fragmentadas e Viabilidades de Recuperação para a sub-bacia do rio Claro $(G O)$, Tese (Doutorado), Instituto de Estudos Socioambientais da Universidade Federal de Goiás, 2011.

FARIA, K. M. S.; CASTRO, S. S. Análise da evolução da fragmentação da paisagem com uso de geotecnologias na sub-bacia do Rio Claro, entre 1990 e 2008, Brasil Central. In: II SEMINÁRIO IBERO-AMERICANO DE GEOGRAFIA FÍSICA / VI SEMINÁRIO LATINO-AMERICANO DE GEOGRAFIA FÍSICA. Universidade de Coimbra, Maio de 2010. Anais..., Coimbra, 2010.

FERREIRA, A. B.; ALCOFORADO, M. J.; VIEIRA, G. T.; MORA, C.; JANSEN, J. Metodologias de análise e de conservação das paisagens: o exemplo do projecto estrela. Finisterra. XXXVI. 72: 157$178,2001$.

FISZON, J. T.; MARCHIORO, N. P. X.; BREITEZ, R. M.; CABRAL, D. C.; CAMELY, N. C.; CANAVESI, V.; CASTELLA, P. R.; CASTRO, E. B. V.; JUNIOR, L. C.; CUNHA, M. B. S.; FIGUEIREDO, E. O.; FRANKE, I. L.; GOMES, H.; HREISEMNOU, V. H. V.; LANDAU, H. C.; LIMA, S. M. F.; LOPES, A. T. L., NETO, E. M.; MELLO, A. L.; OLIVEIRA, L. C.; ONO, K. Y.; PREREIRA, N. W. V.; RODRIGUES, A. A. F.; RUIZ, C. R.; SANTOS, L. F. G. L.; SMITH, W. S. \& SOUZA, C. R. Causas Antrópicas. In: RAMBALDINI, D. M.; OLIVEIRA, D. A. S. Fragmentação de ecossistemas: causas, efeitos sobre a biodiversidade e recomendações de políticas públicas. $2^{\mathrm{a}}$ ed. Brasília: MMA/SBF, 2005.

FORMAN, R. T. T.; GODRON, M. Landscape ecology. New York: John Wiley ans Sons, 1986. 619 p.
MARTINS, E. S.; REATTO, A.; CARVALHO JÚNIOR, O. B.; GUIMARÃES, R. F. Ecologia de paisagem: conceitos e aplicações no Brasil. Planaltina: Embrapa Cerrados, 2004.

MCGARIGAL, K.; MARKS, B. Fragstats: spatial pattern analysis program for quantifying landscape structure. US Dept. of Agriculture, Forest Service, Pacific Northwest Research Station, 1995.

MESQUITA JUNIOR, H. N. Análise temporal com sensor orbital de unidades fisionômicas de cerrado na gleba Grande Pé de Gigante (Parque Estadual de Vassunga-SP). Dissertação (Mestrado em Ecologia dos Ecossistemas terrestres e aquáticos) Instituto de Biociências, Universidade de São Paulo. São Paulo. 1998.

METZGER, J. P. O que é Ecologia de Paisagens. Biota neotropica, v.1, n.1, p. 1-9, 2001.

MORAES, A. C. R. Geografia: pequena historia crítica. São Paulo: Hucitec, 1991.

MOREIRA, R. Marxismo e Geografia: a geograficidade e o diálogo das ontologias. Geographia, v.6 (11), p.21-37, 2004.

NAVEH, Z. Ecosystem and landscapes: A critical comparative appraisal. Journal of Landscape Ecology, v.3 (1), p. 64-81, 2010.

NAVEH, Z.; LIEBERMAN, A. S. Landscape Ecology: Theory and Application. New York/ Berlin / Heidelberg / Tokyo: Springer Series on Environmental Management, 1984

NUCCI, J.C. Origem e desenvolvimento da ecologia e da ecologia da paisagem. Revista Eletrônica Geografa, v. 2 (1), p.77-99, 2007.

OLIFIERS, N.; CERQUEIRA, R. Fragmentação de habitat: efeitos históricos e ecológicos. In: ROCHA, C. F. D.; BERGALLO, H. G.; SLUYS, M. V.; ALVES, M. A. S. Biologia da Conservação: Essências. São Carlos: Rima, 582p. 2006. 
PIRES, A. S.; FERNANDEZ, F. A. S.; BARROS, C. S. Vivendo em um mundo em pedaços: efeitos da fragmentação florestal sobre comunidades e populações animais In: ROCHA, C. F. D.; BERGALLO, H. G.; SLUYS, M. V.; ALVES, M. A. S. Biologia da Conservação: essências. São Carlos, SP: Rima, 2006.

RICKLEFS, R. E. A economia da natureza. Rio de Janeiro: Guanabara Koogan, $5^{\mathrm{a}}$ ed., 2003.

RODRIGUEZ, J. M. M.; SILVA, E. V.; CAVALCANTI, A. P. B. Geoecolgia das paisagens: uma visão geossitêmica da análise ambiental. 2 ed. Fortaleza: Edições UFC, 2007. 222 p.

ROSS, J. L. S. Ecogeografia do Brasil: subsídios para planejamento ambiental. São Paulo: Oficina de Textos. 2006.

SANTOS, M. A Redescoberta da Natureza. Aula Inaugural em 10 de março de 1992. Universidade de São Paulo. Faculdade de Filosofia e Ciências Humanas. 1992.
SCHIER, R. A. Trajetórias do conceito de paisagem na geografia. $R A^{\prime} E G A$. n.7, p.79-85, 2003.

SOARES FILHO, B. S. Modelagem da dinâmica da paisagem de uma região de fronteira de colonização amazônica. Tese (Doutorado), Escola Politécnica, Universidade de São Paulo. São Paulo, 1998.

TABARELLI, M.; GASCON, C.. Lições da pesquisa sobre fragmentação: aperfeiçoando políticas e diretrizes de manejo para a conservação da biodiversidade. Megadiversidade. n.1 (1), p.181-188, 2005.

VITTE, A. C.; SILVEIRA, R. W. D. A paisagem em Alexander von Humboldt: símbolo e linguagem no romantismo alemão de início do século XIX. Caderno Prudentino de Geografia. v.32 (1), p.5-22, 2010. 